\title{
Article
}

|||||||||||||||||||||||||||||||||| $\mid$

\section{Collimator-based Coincidence Imaging for Double Photon Emitting Nuclides}

\author{
M. Amin Choghadi ${ }^{1,}{ }^{\dagger}$, Mizuki Kitajima ${ }^{1}$, Mizuki Uenomachi ${ }^{2}$, \\ Kenji ShimazoE $^{1}$ and Hiroyuki TAKAHASHI ${ }^{1,2,3}$ \\ ${ }^{1}$ Department of Bioengineering, The University of Tokyo, \\ ${ }^{2}$ Department of Nuclear Engineering and Management, The University of Tokyo, \\ ${ }^{3}$ The Institute of Engineering Innovation, The University of Tokyo \\ †amin@sophie.q.t.u-tokyo.ac.jp \\ Received July 24, 2020 \\ Accepted February 4, 2021
}

\begin{abstract}
We have proposed a new concept of time/position correlation type tomographic method based on a directionality-sensitive gamma camera, which can identify incident $\gamma$-ray direction. This method utilizes the correlation between two $\gamma$-ray photons and provides the radioactivity concentration in the body with a high resolution and a high signal-to-noise ratio. ${ }^{111}$ In is known as a cascade $\gamma$-ray emitting nuclide. Besides ${ }^{111}$ In, we have explored new candidates and found some other nuclides with different lifetimes. A focused lead collimator was designed and coupled to a pixelated detector array for this new coincidence imaging modality. The method shows a significant background rejection and an improved spatial resolution in comparison with the single-photon analysis.
\end{abstract}

Key Words: Double-Photon Emission Computed Tomography, coincidence detection, multi-nuclide imaging

\section{Introduction}

Nowadays, Positron Emission Tomography (PET) is widely used in Nuclear Medicine. It shows a very high sensitivity compared with Single Photon Emission Computed Tomography (SPECT) as it does not require a collimator. In SPECT, a large portion of radiated photons is rejected by the collimator. In addition, PET shows a very high signal-to-noise ratio (SNR) since the detection system relies on a coincidence signal where two detectors identify the event. The coincidence signal can highly restrict the target event when the system has a very short time window for the coincidence. As a result, a high SNR is realized. However, PET only uses $511 \mathrm{keV} \gamma$ rays. Thereby, the choice of radionuclide for PET is limited to the positron-emitting nuclides, and it cannot distinguish between them.

Some radionuclides successively emit two gamma photons in a very short time. The use of such gamma photons enables a new type of coincidence imaging method. Recently, we have proposed a new concept of time-and-position correlation-type tomographic method based on a directionality-sensitive gamma camera. ${ }^{1,2)}$ In this concept, we need a nuclide that emits two photons in a relatively short period. So far, we have proposed the use of ${ }^{111} \mathrm{In},{ }^{134} \mathrm{Cs}$, and ${ }^{60}$ Co. ${ }^{1-3)}$ The decay scheme of ${ }^{111} \mathrm{In}$ is shown in Fig. 1.4) It emits a $171.3 \mathrm{keV}$ photon and after the lifetime of $84.5 \mathrm{~ns}$, it emits a $245.4 \mathrm{keV}$ photon. When the system identifies the $171.3 \mathrm{keV}$ photon, it waits for a $245.4 \mathrm{keV}$ photon for about $300 \mathrm{~ns}$. If the system recognizes the $245.4 \mathrm{keV}$ photon, it records two gamma photons and their incident angles and proceeds to the 


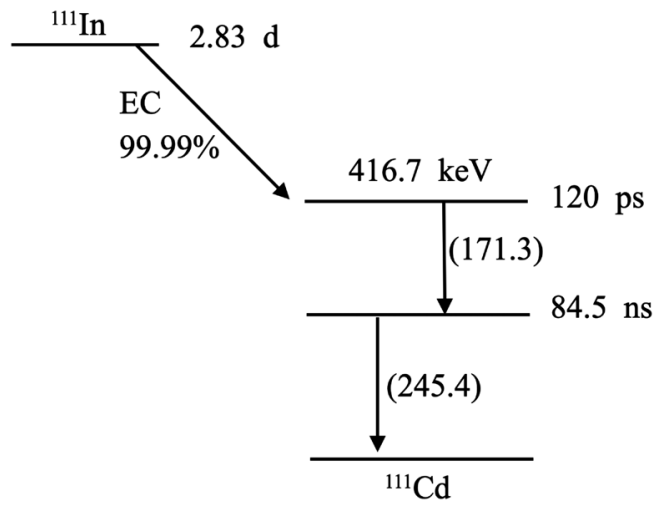

Fig. 1 The decay scheme of ${ }^{111}$ In. $\left.{ }^{4}\right)$

next measurement. To record the angles, a Compton Camera can be used for $300-600 \mathrm{keV} \gamma$ rays; however, a collimator-based imager can be used for low-energy $\gamma$ rays where Compton scattering is not dominant. This enables the collimator-based Double Photon Emission Computed Tomography (DPECT). Previously, a double-photon imager was developed by using two parallel-hole collimators coupled to scintillator detectors, that were placed at a $90^{\circ}$ angle with respect to each other. ${ }^{3)}$ In this paper, we investigated another DPECT method where a focused collimator was used to scan the region of interest. This enables us to view a microscopic distribution of a double-photon-emitting sample and it also provides a large solid angle when many detector modules are used to surround the sample.

\section{Double-photon-emitting radionuclides}

Although ${ }^{111}$ In is feasible for the measurement, the advantage of the double-photon imaging lies in its multi-nuclide capability. Therefore, we explored other candidates for this method. In medical applications, the half-life of radionuclide should not be too short or too long. The double-photon yield should be large, and the correlated photons should be emitted within a short span. Besides, the energies of the two photons should not be too large since the detection efficiency for high-energy $\gamma$ rays is limited. After

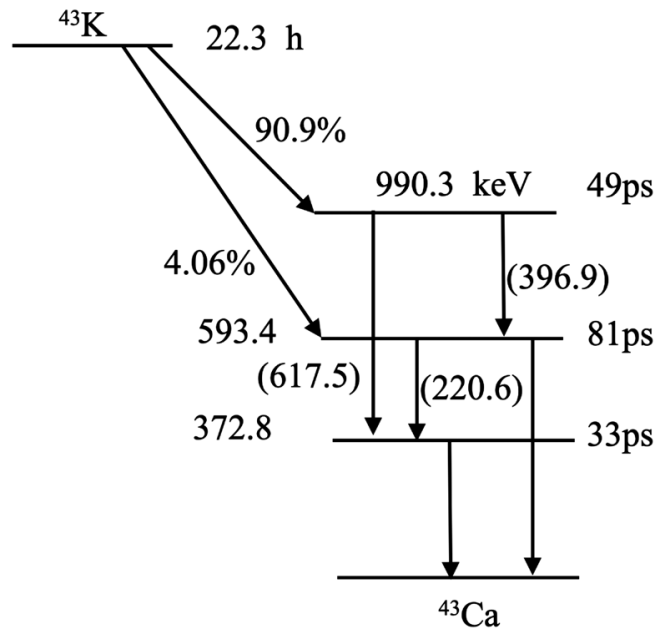

Fig. 2 Partial decay scheme of ${ }^{43} K^{.5}$ )

screening the radionuclides for these requirements, the choice is limited to ${ }^{43} \mathrm{~K},{ }^{48} \mathrm{Cr}$, and ${ }^{177} \mathrm{Lu}$.

${ }^{43} \mathrm{~K}$ is a $\beta^{-}$-emitting nuclide that emits $\gamma$ rays upon emission of a $\beta^{-}$particle. Its half-life is $22.3 \mathrm{~h}$, which is within reasonable values. Its partial decay scheme is shown in Fig. 2.5) It emits three pairs of gamma photons. The first pair is a $617.5 \mathrm{keV}$ photon $(79 \%)$ and a $372.8 \mathrm{keV}$ photon (87\%). The second pair is a $396.9 \mathrm{keV}$ photon (11.9\%) followed by a $593.4 \mathrm{keV}$ photon (11.3\%). And the third one is a $220.6 \mathrm{keV}$ photon (4.8\%) followed by a $372.8 \mathrm{keV}$ photon. The longest lifetime is $81 \mathrm{ps}$. Therefore, two gamma photons are almost observed simultaneously in the measurement system. The time resolution is almost as close as positron annihilation. Even the time-offlight (TOF) method can be applied to localize the event in the case of this nuclide.

The half-life of ${ }^{48} \mathrm{Cr}$ is $21.56 \mathrm{~h}$, and its primary decay mode is electron capture (EC). ${ }^{6}$ Fig. 3 depicts the decay scheme of ${ }^{48} \mathrm{Cr}$. The pair of a $112.3 \mathrm{keV}$ photon $(96 \%)$ and a $308.3 \mathrm{keV}$ photon $(100 \%)$ can be used for coincidence imaging. The energies of these gamma photons are relatively low. Therefore, the detection system can be compact for this nuclide. The lifetime of the second photon emission in ${ }^{48} \mathrm{Cr}$ is $7.09 \mathrm{~ns}$ that is smaller than that of ${ }^{111} \mathrm{In}$ but much 


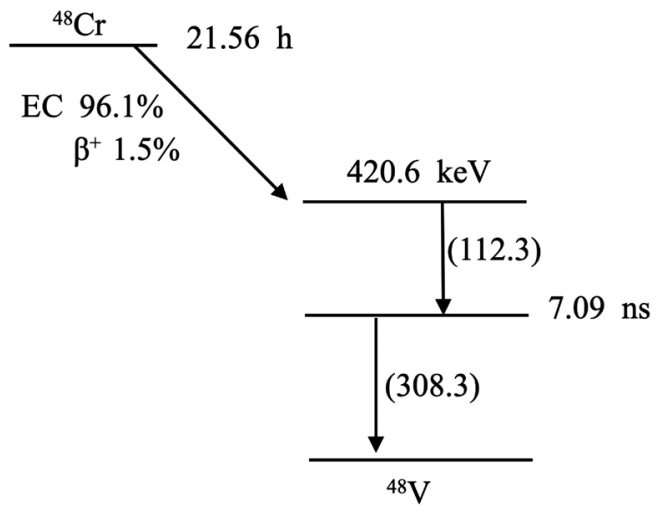

Fig. 3 Partial decay scheme of ${ }^{48} \mathrm{Cr}^{6}{ }^{6}$

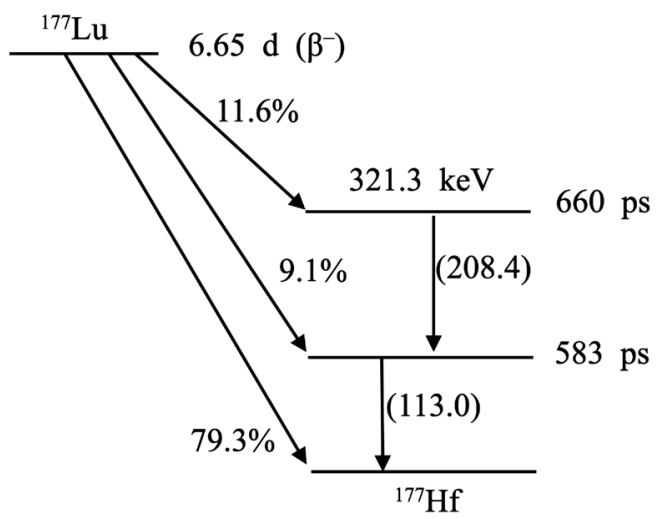

Fig. 4 The decay scheme of ${ }^{177} \mathrm{Lu}^{7}{ }^{7}$

longer than that of ${ }^{43} \mathrm{~K}$. Therefore, it is difficult to apply the TOF method to ${ }^{43} \mathrm{~K}$.

In addition to ${ }^{111} \mathrm{In},{ }^{43} \mathrm{~K}$, and ${ }^{48} \mathrm{Cr}$, the radionuclide, ${ }^{177} \mathrm{Lu}$, shows a double-photon emission process as well. Its decay scheme is shown in Fig. 4. ${ }^{7)}$ However, its double-photon emission rate is merely $11.6 \%$. And in practice, usually a very large amount of radioactivity is applied; therefore, the background is quite strong. Coincidence imaging is advantageous in this sense as it rejects the background extensively. These nuclides can be used for simultaneous multinuclide measurement. This is a potential advantage of double-photon imaging. The radionuclides could be identified either through the pulse-height measurement or by setting different coincidence time windows. Although the pulse-height measurement is more effective for detailed analysis of the events, the use of a coincidence time window comes in handy in the case of fast scintillator systems with relatively poor energy resolution.

\section{Materials and methods}

Previously, we proposed Compton imaging to track the direction of incident photons and extract the coincidences to localize the radiation source. ${ }^{1,2)}$ However, Compton imaging has complications both in mechanical design and in image reconstruction. Moreover, Compton imaging is more common in nuclear physics with high-energy $\gamma$ rays where Compton scattering dominates over the photoelectric effect. In medical applications with low-energy gamma emitters such as ${ }^{111} \mathrm{In}$ and ${ }^{177} \mathrm{Lu}$, this method is not so practical. There are few applications of Compton Camera in medicine, basically for on-line monitoring during proton/neutron therapy where high-energy $\gamma$ rays are emitted as a subsequent process of heavy-particle interaction with tissue. ${ }^{8)}$

On the other hand, collimator-based imagers are highly directional-sensitive and are able to detect radioactivity in small objects with a high detection efficiency. Previously, we proposed a system with a pair of parallel-hole collimators coupled individually to the detector arrays, which were placed at a $90^{\circ}$ angle with respect to each other to provide a grid for detection. ${ }^{3)}$ However, that method suffered a poor coincidence detection efficiency and only $0.134 \%$ of single events were paired as a very limited angular correlation was allowed for detection.

In this work, we proposed another DPECT method with a focused collimator to improve detection efficiency. The concept of this method is shown in Fig. 5. In this method, only one module is used which scans one point over a specific time through a stepand-scan procedure. Unlike the previous method, any combination of detector pixels for coincidence detection is allowed and thus it has a much better 


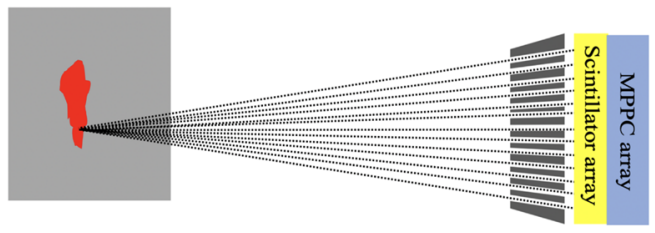

Fig. 5 The concept of a double-photon gamma scanner. Since the detection relies on coincidence, the camera only detects activity on the focal point over a predefined time (Color online).
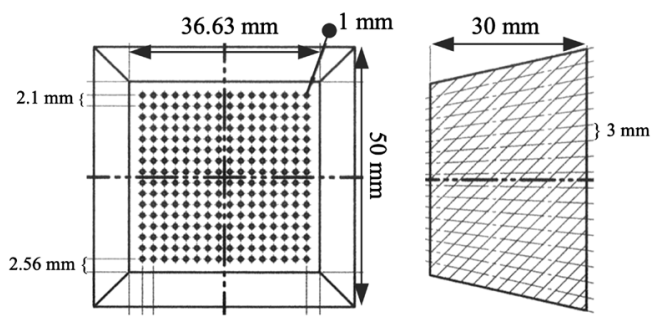

Fig. 6 Dimensions of the focused lead collimator. The focal point of the collimator is $70 \mathrm{~mm}$ from the front face.

coincidence detection efficiency. Theoretically, with the same hole size and collimator thickness, the same detector with 64 pixels, and the same distance between the source and the detector array, the coincidence detection efficiency should be about 64 times that of the previous method.

\section{$3 \cdot 1$ Collimator design}

A $30 \mathrm{~mm}$-thick lead collimator with 256 holes $(16 \times 16)$ and a focal point of $70 \mathrm{~mm}$ from the front face was designed and fabricated with a hole diameter of $1 \mathrm{~mm}$, and a $3 \mathrm{~mm}$ pitch at the backside for a small prototype of a double-photon gamma scanner. The overall dimension is $50 \times 50 \mathrm{~mm}^{2}$ at the backside and $36.63 \times 36.63 \mathrm{~mm}^{2}$ at the front face (see Fig. 6).

\section{$3 \cdot 2$ Detector array}

In this early evaluation of the method, an available MPPC array (Hamamatsu S13361-3050NE-08) was used. The MPPC array had 64 pixels $(8 \times 8)$ with a $3.2 \mathrm{~mm}$ pitch. It was coupled to a GAGG

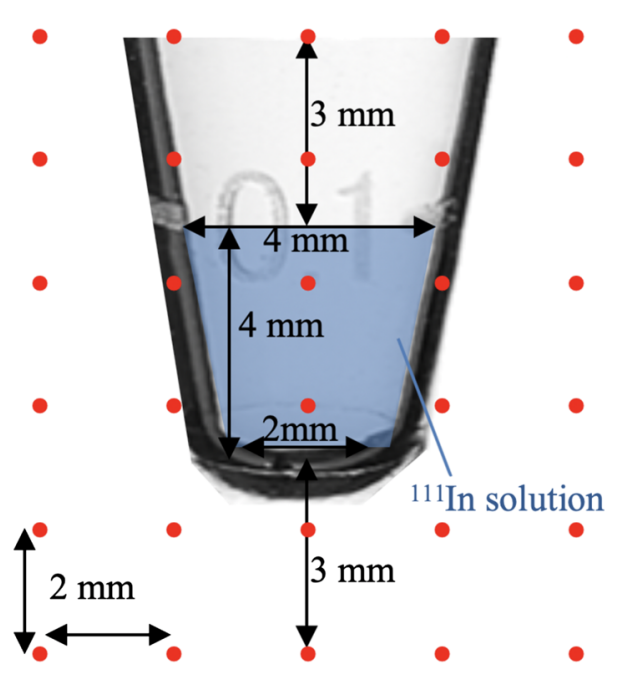

Fig. 7 Coronal plane of the source being scanned with a $2 \mathrm{~mm}$ step size. The red points are the scanned positions. The area being scanned at each position had a $1 \mathrm{~mm}$ diameter (Color online).

scintillator array with the same pitch and crystal size of $2.5 \times 2.5 \times 4 \mathrm{~mm}^{3}$. The $0.7 \mathrm{~mm}$ gaps were filled with $\mathrm{BaSO}_{4}$ as the reflector. The detector array was coupled to the central 64 holes at the backside of the collimator. The output signals were read out through a 64-channel dynamic time-over-threshold board ${ }^{9)}$ and stored in a data acquisition (DAQ) unit with $2.5 \mathrm{~ns}$ resolution.

\subsection{Experimental setup}

A $1 \mathrm{MBq}{ }^{111}$ In solution was filled at the bottom of a microtube (up to $4 \mathrm{~mm}$ from the bottom). The internal diameter of the microtube was $2 \mathrm{~mm}$ at the bottom and $4 \mathrm{~mm}$ at the top of the solution. 30 points on the coronal plane of the microtube shown in Fig. 7 were scanned with a $2 \mathrm{~mm}$ step size using a linear stage. The camera was placed on the stage in a way that the front face of the collimator was $70 \mathrm{~mm}$ away from the coronal plane of the source. The scanning time was $10 \mathrm{~min}$ for each point.

\section{Results}

Fig. 8 depicts the coincidence time of extracted 


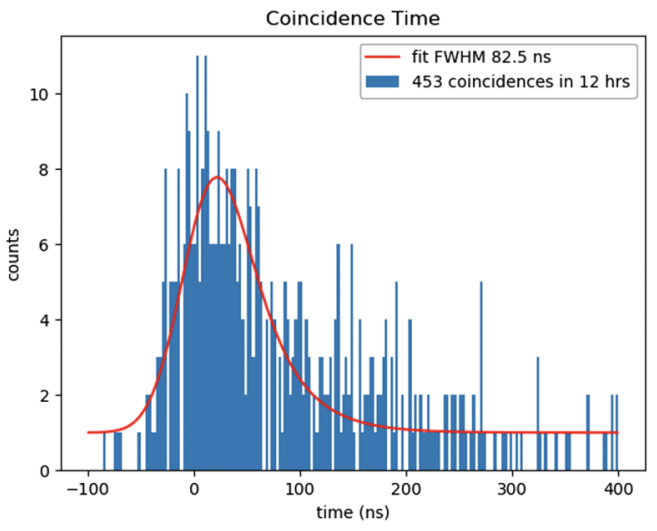

Fig. 8 Coincidence time of extracted double-photons (Color online).

photons. The negative coincidence time is because in some cases the signal for the $245.4 \mathrm{keV}$ photon arrives before the $171.3 \mathrm{keV}$ one in the readout system. The coincidence time follows an exponential decay convoluted with a zero-mean Gaussian distribution that is the typical response of a coincidence detection system. The full-width half-maximum (FWHM) of the fitted curve is $82.5 \mathrm{~ns}$ that is close to the 84.5 -ns lifetime of ${ }^{111}$ In secondary emission.

The low coincidence count rate is coming from the fact that we covered a very small solid angle by using only 64 channels and the coincidence probability is proportional to the square of the solid angle. Only $0.028 \%$ of the single events were paired. This value is much smaller than what was reported in 3) due to the longer distance between the source and the front face of the detector array $(100 \mathrm{~mm})$ as well as the smaller collimator hole size. Considering these two factors, we expected that about $0.024 \%$ of single events would be paired ( 0.18 times the value in 3$)$ ).

Simply by increasing the size of the camera and covering all the holes with detectors, we can improve the coincidence count rate. The detection efficiency is proportional to the square of solid angle in the case of coincidence detection. Therefore, a $16 \times 16$ detector array improves the detection efficiency by a factor of 16. Also, reducing the focal distance from

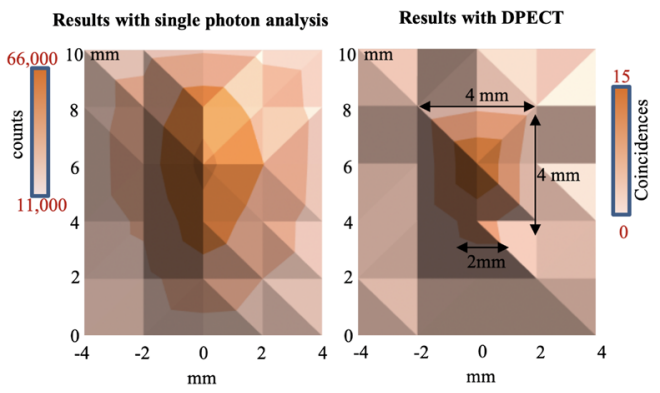

Fig. 9 Comparison of single-photon analysis and doublephoton analysis of ${ }^{111} \mathrm{In}$ solution filled at the bottom of a microtube ( $4 \mathrm{~mm}$ from the bottom). The activity image with DPECT resembles the source more closely. Also, there is no background activity in the case of DPECT (zero counts when the focal point is off the source) (Color online).

the detector surface to $50 \mathrm{~mm}$ provides a 16 times better count rate for the system.

Fig. 9 shows the results of scanning with a $2 \mathrm{~mm}$ step size. As can be seen, in the case of single-photon analysis, even outside the microtube there is a large background (11,000 counts), while in the case of double-photon analysis (DPECT) there is no background and thereby the contrast is much better. The signal to background ratio (SBR) was calculated by dividing the maximum count in the image by the average count of the 18 outer points where there should have been no activity. The SBR of the single-photon analysis is 5.2, while The SBR of DPECT is 25.5 that provides a 5 times better contrast. As a result, the activity map is closer in size to the actual dimensions of the ${ }^{111} \mathrm{In}$ solution even though the step size was $2 \mathrm{~mm}$ that restrains the spatial resolution. To investigate the spatial resolution of the method, measurements with finer step sizes $(0.5$ or $0.2 \mathrm{~mm})$ are required.

\section{Conclusion}

In this study, we proposed a new double photon emission computed tomography (DPECT) technique by using a focused collimator and introduced some double-photon emitting nuclides as candidates for this method. The great advantage of this method over 
single-photon analysis is the extensive background rejection with 5 times better SBR thanks to coincidence detection. PET is also based on coincidence detection. However, this method enables the use of multiple nuclides, it is not restricted to the positronemitting radionuclides, and there is no need for a full ring of detectors.

The main issue, however, is the low coincidence count rate and detection efficiency. The coincidence detection efficiency of the system according to the geometry described in Fig. 6 is $1.6 \times 10^{-7}$, without considering the efficiency of the detectors. This value is the square of detection efficiency of a SPECT system with similar components. However, if several modules are arranged close to the sample, the detection efficiency can be greatly improved. Also, increasing the collimator dimensions and the number of detectors in the array as well as reducing the collimator thickness increase the detection efficiency and coincidence count rate. In the case of small animal studies, even a $30 \mathrm{~mm}$ focal distance is enough. And as long as ${ }^{111} \mathrm{In},{ }^{177} \mathrm{Lu}$, and ${ }^{48} \mathrm{Cr}$ are used, the thickness of the lead collimator could be reduced to $20 \mathrm{~mm}$. Besides, in small animal studies, much higher radioactivity in the order of $50 \mathrm{MBq}$ is usually applied, ${ }^{10,11)}$ which increases the coincidence rate significantly.

\section{References}

1) Yoshihara, Y., Shimazoe, K., Mizumachi, Y. and Takahashi, H., Evaluation of double photon coinci- dence Compton imaging method with GEANT4 simulation, Nucl. Instrum. Meth. A, 873, 51-55 (2017)

2) Uenomachi, M., Mizumachi, Y., Yoshihara, Y., Takahashi, H., et al., Double photon emission coincidence imaging with GAGG-SiPM Compton camera, Nucl. Instrum. Meth. A, 954, 161499 (2020)

3) Shimazoe, K., Uenomachi, M., Mizumachi, Y., Takahashi, H., et al., Double photon emission coincidence imaging using GAGG-SiPM pixel detectors, Jinst, 12, C12055 (2017)

4) Browne, E., et al., edited by Lederer, C. and Shirley, V., Table of Isotopes, pp. 516-523, Wiley, New York (1978)

5) Dhala, A., Mukherjeeb, G., Bhattacharjee, M., Naik, V., et al., Decay measurements of ${ }^{43} \mathrm{~K}\left(\beta^{-}\right)^{43} \mathrm{Ca}$ by HRS and TAS, EPJ Web Conf., 146, 10013 (2017)

6) Burrows, T., Nuclear Data Sheets for $\mathrm{A}=48, \mathrm{Nucl}$. Data Sheets, 107, 1747-1922 (2006)

7) Schötzig, U., Schrader, H., Schönfeld, E., Günther, E., et al., Standardisation and decay data of ${ }^{177} \mathrm{Lu}$ and ${ }^{188} \mathrm{Re}$, Appl. Radiat. Isot., 55, 89-96 (2001)

8) Sato, S., Kataoka, J., Kotoku, J., Taki, M., et al., First application of the super-resolution imaging technique using a Compton camera, Nucl. Instrum. Meth. A, 969, 164034 (2020)

9) Shimazoe, K., Takahashi, H., Shi, B., Orita, T., et al., Dynamic time over threshold method, IEEE Trans. Nucl. Sci., 59, 3213-3217 (2012)

10) Melis, M., Vegt, E., Konijnenberg, M., de Visser, M., et al., Nephrotoxicity in mice after repeated imaging using ${ }^{111}$ In-labeled peptides, J. Nucl. Med., 51, 973-977 (2010)

11) Missault, S., Peeters, L., Amhaoul, H., Thomae, D., et al., Decreased levels of active UPA and KLK8 assessed by [ $\left.{ }^{111} \mathrm{In}\right] \mathrm{MICA}-401$ binding correlate with the seizure burden in an animal model of temporal lobe epilepsy, Epilepsia, 58, 1615-1625 (2017) 
要旨

\title{
2 光子放出核種のためのコリメータ搭載型コインシデンスイメージング
}

\author{
チョガディアミン ${ }^{1, \dagger}$, 北島瑞希 $^{1}$, 上ノ町水紀 ${ }^{2}$, 島添健次 ${ }^{1}$, 高橋浩之 ${ }^{1,2,3}$ \\ 1東京大学大学院工学系研究科バイオエンジニアリング専攻, \\ 2 東京大学大学院工学系研究科原子力国際専攻, \\ 3 東京大学大学院工学系研究科総合研究機構 \\ †amin@sophie.q.t.u-tokyo.ac.jp \\ 2020 年 7 月 24 日 受付 \\ 2021 年 2 月 4 日 受理
}

指向性を持つガンマカメラを用い, 光子の時間・位置の相関情報を取得する新しい断層撮像法 を提案する。体内の薬剤集積情報を得る際，二光子の時間・位置情報を利用することで高い分解 能と SNR（Signal-to-Noise Ratio）が実現可能である。 ${ }^{111}$ In はカスケード $\gamma$ 線を放出する核種として 知られる。 ${ }^{111}$ In に加え, 本手法に適用可能な核種に関して考察する。本手法では, 鉛フォーカシ ングコリメータとピクセル型検出器を組み合わせ，二光子の同時計測を行う。 